\title{
LETTER
}

\section{Pharmacokinetics of anidulafungin during albumin dialysis}

\author{
Gerardo Aguilar ${ }^{1 *}$, José Ramón Azanza², Belén Sádaba², Rafael Badenes ${ }^{1}$, Carlos Ferrando $^{1}$, Carlos Delgado $^{1}$, \\ Javier Hernández ${ }^{3}$, María Asunción Parra ${ }^{2}$, Jaume Puig ${ }^{1}$, José A Carbonell ${ }^{1}$, David Navarro ${ }^{4,5}$ and F Javier Belda ${ }^{1,5}$
}

In the ICU setting, current guidelines recommend echinocandins as the first-line treatment for invasive candidiasis [1]. Albumin dialysis (AD) has been used in the ICU as supportive therapy for hepatic failure, but this technique can significantly enhance drug elimination [2]. We prescribed anidulafungin for suspected invasive candidiasis in a patient with severe liver failure treated with $\mathrm{AD}$ and measured the plasma concentrations of the drug using high-performance liquid chromatography.

This study (GEF-ANI-2010-02) was approved by the local ethics committee (INCLIVA, Institute of Research, Valencia, Spain) and written informed consent was obtained from the patient's next of kin. An adult patient was admitted to our ICU with acute liver failure after major hepatectomy for metastasis. The patient was given anidulafungin (200 mg loading dose on day 1 , followed by $100 \mathrm{mg}$ daily) for suspected invasive candidiasis. On the fourth day, the patient developed encephalopathy and complained of increasing pruritus. AD using the Molecular Adsorbent Recirculating System (Gambro Hospal AG, Zurich, Switzerland) was therefore started while waiting for liver function to improve. Arterial blood, urine, and dialysate samples were collected at different times after the first AD session was initiated: before starting the fourth anidulafungin infusion and at $0.5,1,1.5,2,4,6$, and 8 hours after starting the infusion.
The last samples (8 hours) were obtained when AD was finished. Anidulafungin was well tolerated without relevant adverse effects.

The following pharmacokinetic parameters were calculated: area under the concentration curve from 0 to 8 hours using the linear trapezoidal rule, and the elimination half-life with noncompartmental analysis. The values for the peak plasma concentration, the through plasma concentration, and the time to reach the peak plasma concentration were calculated from the observed values (Figure 1).

Plasma, urine, and dialysate samples were analysed. The limit of quantification was $0.5 \mathrm{mg} / \mathrm{l}$. No anidulafungin levels were measurable in the ultradiafiltrate and urine samples. The peak plasma concentration with the $100 \mathrm{mg}$ dose on day 4 was $9.45 \mathrm{mg} / \mathrm{l}$ (Figure 1).

Only two reports regarding the use of antifungals during $\mathrm{AD}$ were found in the literature, demonstrating that the influence of this technique on drug elimination appeared to be negligible [3,4]. We report the first pharmacokinetic study of anidulafungin during AD. Although the main limitation of our study is the enrolment of only one patient and the sampling being no more than 8 hours, AD appears to have little influence on the pharmacokinetics of anidulafungin and an adjustment of the drug dose is probably not required. However, further research is needed to confirm our findings.

\footnotetext{
* Correspondence: gerardo.aguilar@uv.es

'Surgical Intensive Care Unit, Department of Anesthesiology and Intensive Care, Hospital Clínico Universitario de Valencia, Avenida Blasco Ibanez 17, 406010 Valencia, Spain

Full list of author information is available at the end of the article
} 


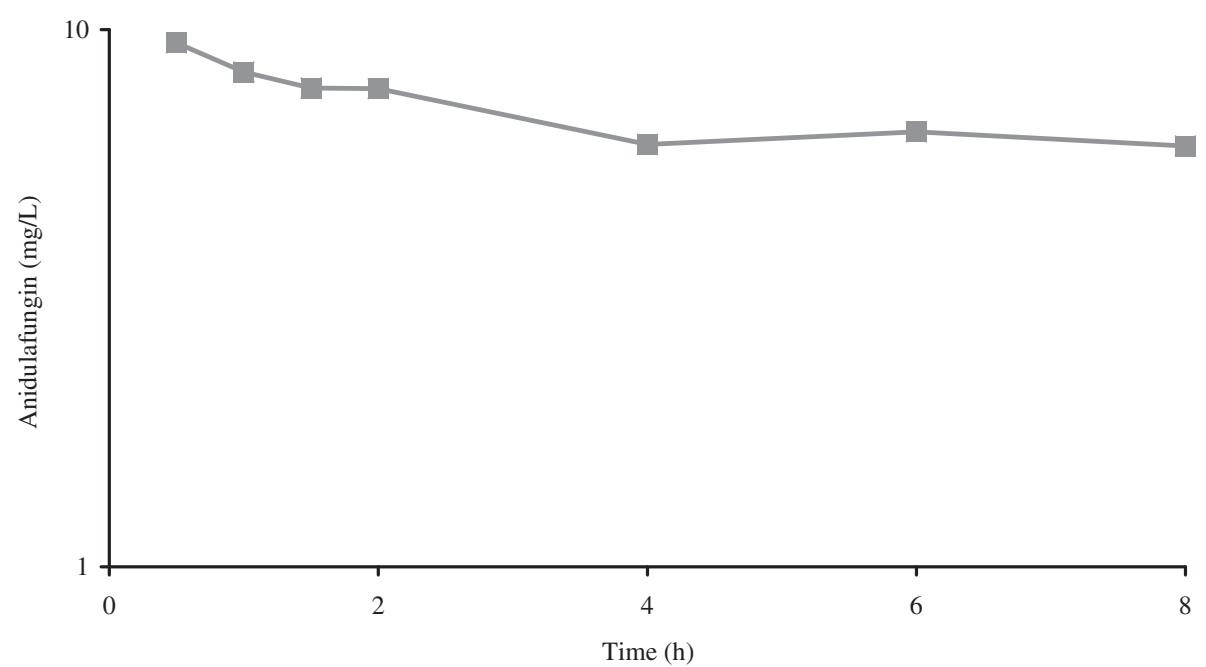

Figure 1 Pharmacokinetics of anidulafungin in a patient on albumin dialysis. The peak plasma concentration with the $100 \mathrm{mg}$ dose on day 4 was $9.45 \mathrm{mg} / \mathrm{l}$. The area under the concentration curve from 0 to 8 hours was 53.70 hours* $\mathrm{mg} / \mathrm{l}$. The elimination half-life was 17.81 hours.

\section{Abbreviations}

AD: Albumin dialysis.

\section{Competing interests}

GA received funds for speaking at meetings organised on behalf of Astellas, Gilead, Merck Sharp and Dohme (MSD), and Pfizer. GA also received unrestricted research grants from Astellas, MSD, and Pfizer. JRA received funds for speaking at symposia organised on behalf of Pfizer, and also received unrestricted research grants from Gilead and Pfizer. DN received funds for speaking at meetings organised on behalf of Astellas, MSD, and Pfizer. DN also received unrestricted research grants from Astellas and Pfizer The remaining authors declare that they have no competing interests.

\section{Authors' contributions}

GA conceived of the study, participated in its design and helped to draft the manuscript. JRA, BS and MAP carried out the pharmacokinetics study and participated in the design of the study. $\mathrm{RB}, \mathrm{CF}, \mathrm{CD}, \mathrm{JP}, \mathrm{JAC}$ and $\mathrm{JH}$ participated in the analysis and interpretation of data. DN and FJB helped to draft the manuscript and participated in the design and coordination of the study. All authors read and approved the final manuscript.

\section{Acknowledgements}

This case report was funded by Pfizer Spain.

\section{Author details}

'Surgical Intensive Care Unit, Department of Anesthesiology and Intensive Care, Hospital Clínico Universitario de Valencia, Avenida Blasco Ibanez 17, 406010 Valencia, Spain. ${ }^{2}$ Department of Clinical Pharmacology, University of Navarra Clinic, Avenida Pío XII 36, 31008 Pamplona, Spain. ${ }^{3}$ Intensive Care Unit, Department of Anesthesiology and Intensive Care, Consorcio Hospital General Universitario de Valencia, Avenida Tres Cruces 2, 46014 Valencia, Spain. ${ }^{4}$ Department of Microbiology, Hospital Clínico Universitario de Valencia, Avenida Blasco Ibanez 17, 46010 Valencia, Spain. ${ }^{5}$ School of Medicine, University of Valencia, Avenida Blasco Ibanez 15, 46010 Valencia, Spain.

Published: 31 Mar 2014

\section{References}

1. Cornely OA, Bassetti M, Calandra T, Garbino J, Kullberg BJ, Lortholary O, Meersseman W, Akova M, Arendrup MC, Arikan-Akdagli S, Bille J, Castagnola E, Cuenca-Estrella M, Donnelly JP, Groll AH, Herbrecht R, Hope WW, Jensen HE, Lass-Flörl C, Petrikkos G, Richardson MD, Roilides E, Verweij PE, Viscoli C, Ullmann AJ, ESCMID Fungal Infection Study Group: ESCMID Fungal Infection Study Group. ESCMID* guideline for the diagnosis and management of Candida diseases 2012: non-neutropenic adult patients. Clin Microbiol Infect 2012, Suppl 7:19-37.

2. Mitzner SR: Albumin dialysis: an update. Curr Opin Nephrol Hypertens 2007, 16:589-595.

3. Vogelsinger $\mathrm{H}$, Joannidis $M$, Kountchev J, Bellmann-Weiler R, Wiedermann CJ, Bellmann R: Pharmacokinetics of liposomal amphotericin B during extracorporeal albumin dialysis. Artif Organs 2006, 30:118-121.

4. Weiler $\mathrm{S}$, Vogelsinger $\mathrm{H}$, Joannidis M, Dunzendorfer $\mathrm{S}$, Bellmann R: Influence of albumin dialysis on pharmacokinetics of amphotericin $B$ colloidal dispersion and amphotericin B lipid complex. Artif Organs 2011, 35:667-671.

\section{$10.1186 /$ cc13805}

Cite this article as: Aguilar et al:: Pharmacokinetics of anidulafungin during albumin dialysis. Critical Care 2014, 18:422 